\section{Suicídio: saindo da sombra em direção a um Plano Nacional de Prevenção}

\author{
Suicide: moving away \\ umbrage towards a \\ National Prevention Plan
}

O suicídio representa um sério problema de saúde pública. Em termos globais, a mortalidade por suicídio aumentou $60 \%$ nos últimos 45 anos. Nesse período, os maiores coeficientes de suicídio mudaram da faixa mais idosa da população para as faixas mais jovens. Na maioria dos países, o suicídio situa-se entre as 10 causas mais freqüentes de morte e entre as duas ou três mais freqüentes em adolescentes e adultos jovens. De acordo com registros da Organização Mundial da Saúde, 900.000 pessoas cometeram suicídio em 2003. Isso representa uma morte a cada 35 segundos. Para cada óbito por suicídio, há no mínimo cinco ou seis pessoas próximas ao falecido cujas vidas são profundamente afetadas emocional, social e economicamente. ${ }^{1}$

O coeficiente de mortalidade por suicídio no Brasil é, em média, 4,5 por 100.000 habitantes ao longo de um ano, considerado relativamente baixo numa escala mundial. No entanto, em certas cidades e regiões, bem como em alguns grupos populacionais (como, por exemplo, o de jovens em grandes cidades, o de indígenas do Centro-Oeste e do Norte e entre lavradores do interior do Rio Grande do Sul), as cifras se aproximam ou superam a de países do leste europeu e da Escandinávia. Os coeficientes de suicídio têm aumentado em nosso país, notadamente entre jovens e adultos jovens do sexo masculino. Outra ponderação: como somos um país populoso, atingimos o nono lugar em número absoluto de suicídios. Os registros oficiais, que devem estar subdimensionados, indicam que houve no país 7.987 suicídios em 2004, o que representou 0,8\% do total de óbitos naquele ano. Dentre os que se mataram, 55\% tinham menos de 40 anos de idade. Nesse grupo, o suicídio respondeu por 3\% do total de óbitos. ${ }^{1}$

Estima-se que o número de tentativas de suicídio supere o de suicídios em pelo menos 10 vezes. O comportamento suicida exerce considerável impacto nos serviços de saúde e calcula-se que $1,4 \%$ da carga (burden) global ocasionada por doenças no ano 2002 deveu-se a tentativas de suicídio. Essa cifra deverá chegar aos 2,4\% em 2020. ${ }^{1}$

0 primeiro estudo de base populacional que fez um levantamento sobre a dimensão de idéias, planos e tentativas de suicídio em países em desenvolvimento foi organizado pela Organização Mundial da Saúde, tendo o Brasil como um dos países participantes. Segundo este estudo, na área urbana do município de Campinas, ao longo da vida, 17,1\% das pessoas "pensaram seriamente em por fim à vida", 4,8\% chegaram a elaborar um plano para tanto e $2,8 \%$ efetivamente tentaram o suicídio. As mesmas prevalências ao longo dos últimos 12 meses foram, respectivamente, 5,3\%, 1,9\% e 0,4\%. ${ }^{2}$

Apesar de o suicídio envolver questões socioculturais, genéticas, psicodinâmicas, filosófico-existenciais e ambientais, na quase totalidade dos casos um transtorno mental encontra-se presente. Uma revisão sistemática de 31 artigos científicos publicados entre 1959 e 2001, englobando 15.629 suicídios na população geral, demonstrou que em $97 \%$ dos casos caberia um diagnóstico de transtorno mental na ocasião do ato fatal. ${ }^{3}$

Em nosso país, até há pouco tempo, o suicídio não era visto como um problema de saúde pública. Entre as causas externas de mortalidade, o suicídio encontrava-se na sombra dos elevados índices de homicídio e de acidentes com veículos, 7 e 5 
vezes maiores, em média e respectivamente. No entanto, a necessidade de se discutir a violência, de modo geral, trouxe à tona o problema do suicídio.

Em final de 2005, o Ministério da Saúde montou um grupo de trabalho com a finalidade de elaborar um Plano Nacional de Prevenção do Suicídio, com representantes do governo, de entidades da sociedade civil e das universidades. Em 14 de agosto de 2006 foi publicada uma portaria com as diretrizes que deverão orientar tal plano. ${ }^{4}$ Dentre os principais objetivos a serem alcançados destacam-se:

1) Desenvolver estratégias de promoção de qualidade de vida e de prevenção de danos;

2) Informar e sensibilizar a sociedade de que o suicídio é um problema de saúde pública que pode ser prevenido;

3) Fomentar e executar projetos estratégicos fundamentados em estudos de eficácia e qualidade, bem como em processos de organização da rede de atenção e intervenções nos casos de tentativas de suicídio;

4) Promover a educação permanente dos profissionais de saúde da atenção básica, inclusive do Programa Saúde da Família, dos serviços de saúde mental, das unidades de urgência e emergência, de acordo com os princípios da integralidade e da humanização.

Antes mesmo da finalização de um Plano Nacional de Prevenção de Suicídio, esperado para 2007, com destinação de verba orçamentária específica, o Ministério da Saúde já lançou um manual de prevenção de suicídio destinado a equipes de saúde mental e uma bibliografia comentada sobre comportamento suicida. Outra publicação destinada ao treinamento de equipes da rede básica de saúde estará disponível brevemente. São boas notícias, que tiram o suicídio da penumbra da negação e do tabu, para encará-lo como um problema de saúde pública.

Há, hoje, considerável informação a respeito do que, em vários países, já foi feito para a prevenção do suicídio, do que deu certo e do que não funcionou. ${ }^{5}$ Já temos evidências científicas disponíveis; agora é esperar o esforço final da área técnica do Ministério da Saúde, para fazer do Brasil o primeiro país da América Latina a elaborar e a executar ações de prevenção do comportamento suicida.

Neury José Botega Departamento de Psicologia Médica e Psiquiatria, Faculdade de Ciências Médicas, Universidade Estadual de Campinas (Unicamp), Campinas (SP), Brasil

\section{Referências}

1. World Health Organization. The World Health Report 2003: Shaping the future. Geneve: World Health Organization; 2003.

2. Botega NJ, Barros MB, Oliveira HB, Dalgalarrondo P, Marin-Leon L. Suicide behavior in the community: prevalence and factors associated to suicidal ideation. Rev Bras Psiquiatr. 2005:27(1):45-53.

3. Bertolote JM, Fleischmann A. Suicide and psychiatric diagnosis: a worldwide perspective. World Psychiatry. 2002;1(3):181-5.

4. Brasil. Ministério da Saúde (2006). Diretrizes brasileiras para um plano nacional de prevenção do suicídio. Portaria n 1.876 de 14 de agosto de 2006.

5. Mann JJ, Apter A, Bertolote J, Beautrais A, Currier D, Haas A, Hegerl U, Lonnqvist J, Malone K, Marusic A, Mehlum L, Patton G, Phillips M, Rutz W, Rihmer Z, Schmidtke A, Shaffer D, Silverman M, Takahashi Y, Varnik A, Wasserman D, Yip P, Hendin H. Suicide prevention strategies: a systematic review. JAMA. 2005;294(16):2064-74.

Financiamento: Inexistente

Conflito de interesses: Inexistente 